\title{
SCIENTIFIC RESEARCH AND DECISION-MAKING PROCESS IN JORDAN: PUBLIC INSTITUTIONS OF SOCIAL DEVELOPMENT AS A MODEL, A QUALITATIVE STUDY
}

\author{
WAFA' ALLAN AL AMAIREH \& DR. MUHAMMAD FAYEZ AL-TRAWNEH
}

University of Jordan, Amman-Jordan

\begin{abstract}
The research aims to explain the role of scientific research in the decision-making process at the public institutions responsible for social development in Jordan and to identify the reasons that limit the role of scientific research in the decision-making process at the public institutions responsible for social development in Jordan.

The research used the purposive sampling through selecting the Secretary-General and Director of Research and Studies in each ministry (2 persons from each ministry), and the total sample size is expected to be 12 participants (males and females). Adopting the qualitative methodology and structured personal interviewing in the research, the research also used a qualitative analytical methodology. The results show that Absence of the concept of scientific research for the study participants whose perspective is limited to academic research that aims to study and diagnose the issues; Varied perceptions of the study participants on the importance of scientific research in the decision-making process and impact of employing scientific research for the individuals and their personal attitude as a scientific activity; Poor coordination between the development agencies and academic research institutions on topics that need research and study through activities of the different academic research institutions; Lack of financial support to implement scientific research and studies at the public institutions operating in the field of social development; Poor methodologies used in the academic scientific research and prolonged time needed to complete them, making it difficult for the decision-makers to utilize them in a timely manner; The main challenges facing the decision-maker to adopt scientific research in the decision-making process include adoption of some research and studies of certain agendas and ideologies, making them biased and non-objective, as well as lack of continuity and unjustified and illogical changes of the decision-maker position.

KEYWORDS: Decision-Making Process, Qualitative Development \& Financial Support
\end{abstract}

Received: Oct 07, 2020; Accepted: Oct 27, 2020; Published: Dec 07, 2020; Paper Id.: IJEEFUSOCT20203

\section{INTRODUCTION}

Decision-making and policy-making process is critical at the society, institution, and individual levels. In addition, it is a major process whenever individuals and institutions plan and implement initiatives to ensure realizing their objectives based on available time and human and financial resources. There are several principles for the decision-making process, irrespective of the field or target group (Al Majali, 2012). For example, the decision-making process usually relies on a set of essential principles and considerations such as objectives, purposes, 
expected outcomes, target group(s), available human, financial, and time resources to ensure decision implementation on the ground. Employing all these elements requires supporting any decision with a scientific and accurate study that helps formulate such a decision on the one hand, and direct the decision-makers towards the right direction. Therefore, scientific research is of great importance as an integral activity for any decision-making process (Hammer, 2008).

Therefore, the decision and policy-making process must rely on scientific research as an integral activity for all decision-making institutions. Equally important, scientific research is needed to measure whether the decisions have been implemented and the ensuing positive or negative outcomes.

\subsection{Research Problem}

A quick review of the sectoral and national strategies, plans, and policies in the field of human and social development in Jordan, which have been designed, developed, and approved by the concerned bodies, shows that there are a significant number of such strategies and plans. These include, for instance, Jordan 2025: National Vision and Strategy, Dimension of Participation in Labor Force, Jordan Renaissance Plan: Government Priorities 2019-2020; Comprehensive National Plan for Human Rights 2016-2025; Jordan Action Plan of Mashreq Gender Facility, Gender Equality, Direct Results; National Employment Strategy 2011-2020; Jordan Economic Growth Simulation Plan 2018-2022; National Strategy for Social Protection and Poverty Reduction 2019-2025; National Strategy for Youth; National Strategy for the Elderly; and National Strategy for Women. In spite of having a strong political and institutional will in terms of making significant efforts and allocating financial and human resources towards designing such strategies, many dimensions of these strategies are still unimplemented, and the monitoring and evaluation function to measure success in implementing such strategies is still weak. This, in turn, has affected trust and social and institutional accountability of the methodology used to develop strategies and plans at the public and private levels.

Add to this, the decision-making process in Jordan faces systemic and institutional challenges and obstacles related to the decision-making process; the mechanisms through which decisions are made by the main institutional structures; the principles and methodology used in making and implementing the decisions; the extent of adopting the research and study approach; as well as quality of research needed in making the different institutional decisions at all local and national levels. The absence of a research-based approach in the decision-making process leads to make shallow decisions, incorrect, and unsustainable decisions on the one hand, and irresponsive to the real needs on the other (Hammer, 2008).

\subsection{Research Questions}

- What is the role of scientific research in the decision-making process at the public institutions responsible for social development in Jordan?

- What are the reasons for limiting the role of scientific research in the decision-making process at the public institutions responsible for social development in Jordan?

- How can the role of scientific research be enhanced in the decision-making process at the public institutions responsible for social development in Jordan?

\subsection{Research Significance}

This research is significant for the following reasons 
1.3.1 Theoretical Significance: Enrich the knowledge base with a study whose results can be used to improve the decision-making process at public institutions in Jordan and shed the light on the importance of scientific research in the decision-making process .

1.3.2 Scientific Significance: Make recommendations that enhance the role of scientific research in the decision-making process at public institutions, in order to come up with realistic and accurate decision to ensure achieving the desired social development.

\subsection{Research Justifications}

Development of this research can be identified as follows :

- Lack of studies addressing the relationship between scientific research and the decision-making process at public institutions in Jordan in general and from the decision-makers' perspective in particular .

- Existing wide gap between results and recommendations of scientific research and the decision-making process at public institutions in Jordan .

- Existing wide gap between needs and priorities of public institutions and scientific research activities in Jordan.

\subsection{Research Objectives}

\section{This Research Aims to Realize the Following Objectives:}

- Explain the role of scientific research in the decision-making process at the public institutions responsible for social development in Jordan.

- Identify the reasons that limit the role of scientific research in the decision-making process at the public institutions responsible for social development in Jordan.

- Make recommendations that enhance the role of scientific research in the decision-making process at public institutions in Jordan.

\subsection{Research Limitations}

\subsubsection{Spatial Limitations}

This research will take place at the public institutions represented by the ministries in Jordan .

\subsubsection{Temporal Limitations}

This research will take place in the period of January-March 2020 .

\subsubsection{Objective Limitations}

Data will be collected through conducting structured personal interviews with 12 participants in the positions of Director of Studies and Research Directorate and Secretary-General of the following ministries (Ministry of Education and Scientific Research, Ministry of Planning and International Cooperation, Ministry of Social Development, Ministry of Youth, Ministry of State for Media Affairs, and Ministry of Labor) .

\subsubsection{Methodological Limitations}

The findings of this research are limited to the level of responsiveness and honesty of the sample population towards the 
questions mentioned in the research tool.

\section{PREVIOUS STUDIES}

\subsection{Arabic Studies}

The study conducted by Al Khazendar (2012) and entitled, The Role of Think tanks and Studies Centers in Scientific Research and Public Policy-making. This study aimed to consider the role of think tanks or studies centers in the field of scientific research from a theoretical perspective as a general framework; from social sciences in general; and from political sciences, international relation, and foreign policy in particular. This was done through surveying several Arabic literatures that addressed the roles of research centers in the society. This research focuses on types of studies and research centers, and their classifications into academic, non-governmental, and of public interest research centers, private sector centers, as well as research centers classified by political and ideological trends, and independence. In addition, the research addressed emergence of research centers and their role and significance in the decision-making and policy-making processes in the world in general and the Arab world in particular, in order to explain the way research centers influence the decision-making and policy-making processes, represented as follows :

- Interactive scientific activities ;

- Workshops and gatherings ;

- Media ;

- Participation in public activities ;

- Direct or personal relationships with the decision-makers; and

- Scientific publications

The research identified the main challenges and obstacles facing the role and effectiveness of studies and research centers in the decision-making process, including financing, objectivity, independence, sustainability, creativity and generation of new ideas. As for research centers in the Arab world, they face poor culture of systemic thinking by many top management officials, overly caution towards openness to new ideas; lack of electronic Arabic database; poor interactive partnership among studies and research centers; and lack of systemic indicators to measure performance and professionalism of research centers.

The study made by Al Majali (2012) addressed contribution of scientific research in development of school management from the perspective of principals in Kerak Governorate using a quantitative approach. It aimed to examine the extent to which scientific research contribute to development of school management from the perspective of principals in Kerak Governorate with a sample of 282 principals. To achieve the research objectives, a questionnaire was developed comprising of 37 paragraphs tackling managerial and technical aspects. The research concluded that scientific research, from the perspective of principals in Kerak Governorate, contributed significantly to development of school management, with a mean of 4.10. The findings also showed statistically significant differences in terms of perspectives of the principals in Kerak Governorate on the extent to which scientific research contribute to development of school management. Such differences are linked to gender variable and managerial experience variable in the technical and managerial fields. The differences were for the interest of females. (Al Majali, 2012)

In his study, Al Nadwi (2019) focused on the importance and role of research centers in the political decisionmaking process. The study showed that research centers have become an integral part of the sovereign institutions and an 
instrumental element in development of policies, future plans, and enlightenment of public opinion. According to the study, such centers influence and contribute significantly to the decision-making process as they provide through studies and accurate analyses to the events and developments facing the countries at the national, regional, and even international levels. Nowadays, research centers play an advanced role in leading global policies and have become a major tool to produce many effective strategic projects. In the Arab world, research centers face several challenges such as limited financing and expenditure on research. Therefore, supporting the role of research centers in the society and country requires a special attention by the decision-makers and policy-makers in the Arab world in general. (Al Nadwi, 2019)

\section{METHOD AND PROCEDURES}

\subsection{Research Methodology}

Usage of the qualitative method to achieve the research objectives .

\subsection{Research Population}

The research population is comprised of all staff of public institutions, represented by Jordanian ministries such as Ministry of Education and Scientific Research, Ministry of Planning and International Cooperation, Ministry of Social Development, Ministry of Youth, Ministry of State for Media Affairs, and Ministry of Labor .

\subsection{Research Sample}

The research used the purposive sampling through selecting the Secretary-General and Director of Research and Studies in each ministry ( 2 persons from each ministry), and the total sample size is expected to be 12 participants (males and females) .

\subsection{Research Tool}

Adopting the qualitative methodology in the research, the structured personal interviewing was used with each participant in the research separately. In this regard, a personal interview guide was developed, comprising of the following sections :

- Introduction, ethical standards, and quality assurance standards

- $\quad$ Profile of the participants: age, gender, title, educational level, and major

- $\quad$ Role of scientific research in the decision-making process at public institutions

- Challenges facing the decision-making process at public institutions in relation to scientific research

- Proposals of the participants on how to enhance the role of scientific research in the decision-making process at public institutions .

\subsection{Statistical Method}

Adopting the qualitative methodology and structured personal interviewing in the research, the research also used a qualitative analytical methodology through the following steps :

- Transfer the interview content to a Excel sheet to be designed in accordance with the personal interview guide

- Clean and codify the data based on primary and secondary codes that will be developed based on available data 
- Analyze the responses based on available data and keywords (most of, some of, and few of)

- Review the findings and support them with citations as said by the participants in addition to examples to explain the findings .

\subsection{Validity and Reliability of the Tool}

Validity and reliability of the tool will be measured through the following procedures :

- Present the tool to three Sociology Professors from the University of Jordan

- Present the tool to three decision-makers in the different public institutions

- Test the tool with three decision-makers in the different public institutions

It is worth noting that development of the tool will be ongoing throughout data collection period by adding a set of questions that will be developed based on the participant responses during the interviews .

\subsection{Procedural Concepts and Definitions}

\subsubsection{Research Concepts :}

- Scientific research: A method used by the researcher for structured and accurate inquiry and investigation in order to discover new information or relationships, and develop, correct, or investigate existing information thoroughly. It is a selection of the necessary method and tools to search for, collect, and analyze information. (Al Khazendar, 2012) .

- Decision-making: Decision-making is the knowledge-based process resulting from selecting the thought or procedure from several possibilities. Each decision-making process leads to a final choice which may lead to take an action, and which may or may not call for taking any action. (Al Fiqqi, 2008)

- Public institutions: A society structure comprising of a set of persons with different professional ranks and titles. They have a specific vision and mission, and they are usually established under a decision published in the Official Gazette. (Abu Zaid, 1985)

\subsubsection{Procedural Definitions}

- Scientific research: The purposive and structured intellectual human effort and activity that aims to develop the necessary scientific knowledge to enhance the decision-making process, verify validity of specific knowledge on a given decision, or provide scientific knowledge that can be employed to develop new decisions or modify existing ones .

- Decision-making: The process used to reach to an appropriate specific action for a given position or status. Such action is agreed upon by a group of persons who hold senior management positions at any ministry or public institution .

- Public institutions: The bodies which are established under a decision published in the Official Gazette and report to the state. For the purposes of this research, public institutions refer to ministries . 


\section{RESEARCH DIFFICULTIES}

\subsection{Chapter One: Decision-making process in Jordan}

This chapter addresses how decisions are made in Jordan through reviewing the related studies and conducting interviews.

\subsection{Chapter Two: Research findings and discussion}

This chapter presents the research findings based on the following sections:

- $\quad$ Section One: The participants, age, gender, title, educational level, and major

- Section Two: Role of scientific research in the decision-making process at public institutions

- Challenges facing the decision-making process at public institutions in relation to scientific research

- Section Three: Proposals of the participants on how to enhance the role of scientific research in the decisionmaking process at public institutions in Jordan.

\section{Chapter Two: Research Findings and Discussion}

This chapter presents the research findings based on the following sections:

- Section One: Role of scientific research in the decision-making process at public institutions

- Section Two: Challenges facing the decision-making process at public institutions in relation to scientific research.

\section{Section One: Role of Scientific Research in the Decision-Making Process at Public Institutions}

All the twelve participants stressed that the decision-making process at public institutions is usually conducted based on the types of decisions made at such institutions as follows:

1. Management decisions: The organizational decisions related to the course of work and administrative matters such as staffing and administrative structure. These decisions are usually made in accordance with the effective regulations, laws, and by-laws of such institutions. For this type, the decisions are formulated using the top-down approach, and these decisions are made in accordance with the powers of the decision-makers and the nature of work at the department or division they manage on the managerial ladder. "Based on the nature of the decision itself, some management decisions start with the client who submit their request to the researcher, to the head of division, to the director, to the SecretaryGeneral, and then to the Minister if needed." (Director of Institutional Development Department, Ministry of Social Development).

2. Technical decisions: They are related to the technical aspects of the institution and result from the tests, measurements, and monitoring and evaluation activities such as the M\&E activities conducted by the M\&E Department at the Ministry of Environment, which are made by the Directorate Director using the bottom-up approach until the decision reaches the Department Director. Such decisions are made based on field visits and pre-developed M\&E reports and forms used by such institution or directorate.

3. Policy and strategy decisions: Some participants indicated that most of such strategies and policies are developed by ad-hoc committees that develop the institution strategy based on the international agreements and state public 
policies such as "Jordan Vision 2025" and then develop the strategy of each ministry for certain periods of time. Such strategies are implemented in coordination and technical supervision of the committees responsible for designing and implementing these strategies, comprising representatives of the technical and management decision-making committees alike to ensure making the appropriate decision that realize the vision or strategy of the institution plan.

\section{Decision-Making Methodology at the Institutions Covered in the Study Sample}

Based on seven representatives in the study sample (e.g. Ministry of Agriculture, Ministry of Social Development, and Ministry of Education), the decision-making process must be conducted based on research and scientific grounds such as referring to the studies and research developed and implemented by the institution, coordinating with all stakeholders and CSOs to obtain related studies, and making use of the research posted on the internet. Therefore, the decision-maker directs the concerned party (i.e. Directorate of Studies and Research) to develop a report or study to explain certain issues, which helps make evidence-based decisions. In addition, the legal or legislative department will review the legislation and develop draft legislation to be discussed by the House of Representatives after obtaining approval of the decision-maker and based on the review of this department and recommendations made by the joint committees. In case there is no need for the decision-maker to ask for a certain study or research, they will comply with the annual plan developed by the directorate of studies and research. Such a plan usually include certain research topics to be addressed within a specific period of time and under the budget allocated for the directorate, which is considered part of the Ministry's overall budget.

As for the Ministry of Youth, they indicated that decisions are made based on the national strategy applied by the Ministry, under which there is a line item in the budget to cover the strategy's implementation. However, due to limited financial and technical resources, it was apparent that the Ministry lacks studies and research addressing the youth-related issues. Such shortage is usually compensated for using social media to survey the youth opinions and find out about their needs or views on a certain decision and its implications before making the final decision by the decision-makers in the Ministry.

Furthermore, some ministries targeted by the study decided to form ad-hoc committees comprising representatives of several institutions whose work interact with the ministry's work such as in the case of the Ministry of Environment. Such committees are tasked with meeting regularly and discussing the decisions to be made, where each committee member provides his/her view on the decision, which is usually based on their knowledge and technical background. Next, the committee members discuss all aspects related to the decisions to be made, and the decision is made in light of the committee's decision, In addition, the Ministry of Environment takes into account the national environmental strategies to ensure achieving its strategic objectives as an integral part of the Ministry's methodology on the one hand, and decisionmaking methodology on the other.

As for the Ministry of Social Development, it was confirmed by its representatives that there are some directives from the Council of Ministers on implementing studies on certain social issues and phenomena such as poverty and child labor. Therefore, some summarized qualitative studies are conducted on such phenomena using the databases of researchers; studies developed previously by the Ministry, and accumulated knowledge of researchers at the Ministry. Moreover, the Ministry of Agriculture emphasized that emerging issues such as diseases and epidemics shifted the decision-making process towards implementing qualitative and quantitative research to ensure taking their findings on outbreak of such disease into account when making any decision by the Ministry. 


\section{Significance of Scientific Research in Decision-Making Process at the Public Institutions}

Asked about the significance of scientific research in decision-making process at their institutions, all the participants (12) stressed the important role of scientific research as a scientific and practical activity in any institution, irrespective of its field. Therefore, absence of scientific research significantly affects development of performance and decisions made by such institutions. They also emphasized that many decisions were made without referring to scientific research, resulting in loss of many efforts and financial resources, as well slow progress in economic growth of Jordan and the institution or ministry. The participants also provided several examples in which the decision-making process relied on scientific research outcomes, and how this proved effective in developing the institution and supporting making realistic decisions, compared to many other situations where the decision-making process did not rely on scientific research, leading to program failure and making arbitrary decisions.

On the other hand, the Ministry of Social Development emphasized that some research and studies provide several contributions and suggestions that develop and accelerate service provision and achieving goals, as well as supporting dynamic sectors to keep in touch with such change. "One of these services is licensing of nurseries. In the past, issuance of nursery permit usually took 8-12 months. However, after conducting a study on nurseries and challenges related to establishing them, and based on the study findings, a decision was made to reduce the time needed to license a nursery to 3 months. In addition, electronic registration service was offered, reducing the licensing period to approximately one month, making things easier for the clients." (Director of Institutional Development, Ministry of Social Development)

Moreover, the Ministry of Youth stressed that the correct and realistic decisions made by the Ministry were the result of research studies, figures, and statistics. In addition, lack of figures and information affects the decision-making process, puts pressure on the Ministry, and creates problems that later on cannot be resolved. "At the beginning of each year, a field survey is conducted to survey needs of the youth in Jordan to employ scientific research in the Ministry's work. Now, we started using ICT and social media as they are trendy for young people. Through such means, we collect and analyze data and develop reports to be used in the decision-making process at the Ministry." (Youth Leader Development Unit, Ministry of Youth)

Similarly, the Ministry of Political and Parliamentary Affairs indicated that the decisions made without referring to scientific research are doomed to fail, and referring to research and studies is not limited to the decision-making process only, but also provides alternatives and implications of each alternative. "During the Parliamentary Election of 2017, the Ministry collected data on the candidates as a simple research activity. Such an activity helped design a database including profile of the candidates along with their objectives and electoral programs. This enhanced the Ministry's knowledge of how candidates think and their common objectives." (Ministry of Political and Parliamentary Affairs)

The research is not the source of all decisions, but supports some decisions where the working team cannot provide the necessary knowledge through the previous studies and research, as well as in the cases where it is difficult to seek internal expertise at the Ministry. Here, we have two options: either to form an internal committee to consider the topic through meetings and brainstorming sessions, or find a source of funding to conduct a study by external experts. Usually, the decision is made without the need for a study or scientific research. (Ministry of Education and Ministry of Youth)

Role of Scientific Research in the Decision-Making Process at Public Institutions 
This section presents the results of questioning the participants on the role of scientific research in the decision-making process with respect to the functions of their institutions and reasons behind this.

In this context, all the participants in the study (12) said that the decision-maker relies on scientific research in the decision-making process at the ministry, but in varied ways depending on the following:

- Type of decisions to be made;

- Attitude of the decision-maker towards the role of scientific research in the decision-making process at the institution; and

- Available time and financial and technical resources to conduct scientific research.

Accordingly, some decision-makers always rely on scientific research outcomes with all of their decisions, even in case of preliminary research and surveys quickly conducted by the ministry's staff (Ministry of Youth and Ministry of Political and Parliamentary Affairs). On the other hand, 6 of the 12 participants indicated that the decision-making process is based on a set of recommendations and proposals made by the joint committees from the ministries and other stakeholders, as in the case of the Ministry of Environment.

As for the Ministry of Social Development, they emphasized that the decision-making process usually relies on an implicit or explicit knowledge of the topic under consideration at the Ministry. "It is unnecessary to conduct research for each decision made, but we can rely on the accumulative knowledge at the Ministry, along with similar studies and research on the subject matter." (Ministry of Social Development and Ministry of Education)

Section Two: Challenges Facing the Decision-Making Process at Public Institutions in Relation to Scientific Research

The participants in the study (12) agreed on a set of challenges that usually face employing scientific research in the decision-making process at the public institutions they represent. These challenges can be presented as follows:

- Different perspectives of the decision-makers on the importance of scientific research in the decision-making process at the institute;

- Financial challenges represented in moderate financial allocations for conducting scientific research at all public institutions and ministries. Even when such allocations exist, they are insufficient to conduct accurate and specialized scientific research;

- Abundance of quantitative research and studies with recurrent topics, problems, objectives, and outcomes, and absence of qualitative and in-depth research addressing topics related to functions of the ministries and public institutions, meeting their needs, and keeping in touch with their developments; "In the social arena, in general, there is a significant shortage of quality rather than quality of research. In other words, there are a massive number of researches in humanities in Jordan, especially in master theses and doctoral dissertations. However, the question is to what extent such research are related to the development sector in Jordan, as they address topics irrelevant to real issues or required services, leading to create a gap between the needs of these research and information institutions and topics of such research along with their findings and outcomes." (Director of Institutional Development, Ministry of Social Development) 
1. The need for academic and non-academic research centers to address the most appropriate topics for the local and national social context and related challenges. In addition, such centers in touch with the technological and information revolution to ensure from such research in a timely fashion;

2. Irrelevance of traditional scientific research (master theses and dissertations) to the needs of decision-makers; "Scientific research theoretical aspects which are of no importance for the decision-maker for realistic and accurate results and figures to inform their decisions. General, Ministry of Youth);

Some decision-makers
are reluctant of research
and researchers, as they
are afraid that excellent
researchers and thinkers
may compete for the
decision-maker's
position. Ministry of
Political and
Parliamentary Affairs
should keep utilization

doctoral focus on who looks "(Secretary-

3. Poor scientific and methodological content of the studies and research of research centers and national academic institutions, ignorance of realities, and weak methodologies used in achieving results are among the limitations to adopt such research and their outcomes in institutionalizing their use in the decision-making process at the public institutions. "Some studies cannot be even sold on the street due to their poor scientific and methodological content" (Advisor to the Secretary-general, Ministry of Political and Parliamentary Affairs);

4. Poor interest by the government and public institutions in scientific research activities and lack of financial support to boost excellent research and researchers. "Some young researchers present their research in the GCC countries or Europe. Then we are surprised to know that they are Jordanian researchers, but they did not receive appropriate attention in Jordan." (Youth Leader Development Unit, Ministry of Youth);

5. Lack of continuity and unjustified and irrational changes in the position of decision-maker in the different institutes, affecting accumulation and building a scientific approach that adopts research outcomes in the decision-making process. "Adopting the methodology, vision, and style of the decision-maker who is usually replaced after short periods of time prevents institutionalizing a clear research and knowledge approach to be adopted at the ministry, irrespective of the persons in charge of the decision-making process itself. (Advisor to the Secretary-general, Ministry of Political and Parliamentary Affairs);

\section{Some decision- makers prefer to relyon knowledge and practical experience of the ministry's staff to enhance the decision-making process.}

6. Poor credibility of research and studies, as the participants confirmed that they had witnessed many situations in which findings of some research contradicted with the ministry's studies, preventing utilization of findings of such research in the decision-making process at the ministry. (Advisor to the Secretary-general, Ministry of Political and Parliamentary Affairs);

7. Some research and studies adopt certain agendas and ideologies, making them biased and non-objective and preventing public institutions from making use of their outcomes. "Some research and studies aim for profits and lose their credibility in terms of the content on the one hand, and their authors on the other. Of course we do not generalize, but some entities are not somehow neutral." (Ministry of Political and Parliamentary Affairs);

8. Lack of content and methodology in the research conducted by several research and academic institutions and absence of survey research that provide a perspective and outlook for the decision-maker in certain fields to envision the future and make decisions that help enhance institutional ability to predict and prepare for the future at all level. (Ministry 
of Political and Parliamentary Affairs, and Ministry of Social Development);

9. Lack of dedication of academic researchers and appointment of several of them in the decision-making position which affect researcher credibility and outcomes of some research. "The researcher and academia should be dedicated, neutral, and away from the authority to avoid conflict of interest and enhance credibility of such research and their recommendations." (Ministry of Political and Parliamentary Affairs, and Ministry of Social Development);

10. Poor experience and knowledge of state institutions and ministries on scientific research and its methodologies and tools, undermining the significance of scientific research and its reflection on the decision-making process in the institution; as well as lack of a participatory approach between public institutions and CSOs which can be a means to enhance scientific research-based decisions. "There is a gap between CSOs that have experience in developing research and studies that can be useful for the different public institutions. This is also related to poor coordination and collaboration between the public institutions and CSOs in different fields, including research and studies." (Ministry of Environment);

The matrix below shows the challenges above according to the entity or institution. Lack of content and methodology in the research conducted, poor experience of the research and studies institutions, poor level of credibility, attitude of the decision-maker towards the importance of relying on research in the decision-making process, and lack of sufficient resources and financial allocations for research activities were the main challenges according to the study participants.

\begin{tabular}{|l|l|}
\hline \multicolumn{1}{|c|}{ Challenges/reasons } & Entity/institution \\
\hline $\begin{array}{l}\text { Poor experience and knowledge of state institutions and ministries on scientific research and } \\
\text { its methodologies and tools }\end{array}$ & 7 \\
\hline Lack of dedication of academic researchers & 10 \\
\hline $\begin{array}{l}\text { Lack of content and methodology in the research conducted by several research and academic } \\
\text { institutions and absence of survey research }\end{array}$ & 12 \\
\hline $\begin{array}{l}\text { Some research and studies adopt certain agenda and ideology, making them biased and non- } \\
\text { objective }\end{array}$ & 5 \\
\hline Poor level of credibility of some research and studies & 12 \\
\hline Lack of continuity and unjustified and irrational changes in the position of decision-maker & 10 \\
\hline $\begin{array}{l}\text { Poor interest by the government and public institutions in scientific research activities and } \\
\text { lack of financial support to boost excellent research and researchers }\end{array}$ & 10 \\
\hline $\begin{array}{l}\text { Abundance of quantitative research and studies with recurrent topics, problems, objectives, } \\
\text { and outcomes }\end{array}$ & 9 \\
\hline $\begin{array}{l}\text { Varied attitudes of the decision-maker on the significance of scientific research in the decision- } \\
\text { making process in the institution }\end{array}$ & 12 \\
\hline
\end{tabular}

\section{FINDINGS}

The study reached a number of findings as follows:

- Absence of the concept of scientific research for the study participants whose perspective is limited to academic research that aims to study and diagnose the issues; 
- Varied perceptions of the study participants on the importance of scientific research in the decision-making process and impact of employing scientific research for the individuals and their personal attitude as a scientific activity;

- Poor coordination between the development agencies and academic research institutions on topics that need research and study through activities of the different academic research institutions;

- Lack of financial support to implement scientific research and studies at the public institutions operating in the field of social development;

- Poor methodologies used in the academic scientific research and prolonged time needed to complete them, making it difficult for the decision-makers to utilize them in a timely manner;

- The main challenges facing the decision-maker to adopt scientific research in the decision-making process include adoption of some research and studies of certain agendas and ideologies, making them biased and nonobjective, as well as lack of continuity and unjustified and illogical changes of the decision-maker position.

\section{REFERENCES}

1. Al Khazendar, Sami et al., 2012, "Role of Think Tanks and Studies Centers in Scientific Research and Public Policy-making, Papers of Politics and Law", Issue No. 7, the Hashemite University.

2. Abu Zaid, Ahmed, 1985, "Social Structure: The Concepts", General Egyptian Commission of Books, Alexandria.

3. Al Fiqqi, Ibrahim, 2008, “Art and Secrets of Decision-making”, Bidaya for Media Production, Cairo.

4. Humra, Y. A. S. H. B. A. "Behavioral finance: An introduction to the principles governing investor behavior in stock markets." International Journal of Financial Management 5.2 (2014): 23-30.

5. Badir, Ahmed, 1989, "Principles and Methodologies of Scientific Research”, Dar Al Ma'aref, Egypt.

6. Qannu', Nizar Saqer, 2006, “Current Situation of Arabic Scientific Research: A Necessity and Related Role of University”, published research paper.

7. Rai, Anjana, and Jawaharlal Nehru. "POLITICAL EMPOWERMENT OF WOMEN IN INDIA: STATUS AND CHALLENGES." International Journal of Humanities and Social Sciences (IJHSS) 7.4, Jun - Jul 2018; 9-18

8. Yousfi, Heddah, 2012, "Obstacles of Relying on Psychosocial Research Findings in Decision-making and Policy-making in Algeria”, Batna University, the First National Symposium on Social Sciences Issues in Algeria: Realities and Perspectives, March 7-8, 2012.

9. Al Majali, Laila, 2012, "Contribution of Scientific Research to Development of School Management from Perspective of Principals in Kerak Governorate", A master thesis, Mu'ta University, Kerak.

10. Abd-elfattah, M. O. H. A. M. E. D., T. U. R. K. I. Alghamdi, and E. S. L. A. M. Amer. "Dashboard technology based solution to decision making." International Journal of Computer Science Engineering 4.2 (2014): 59-70.

11. Al Nadwi, Muhsen, 2019, "Significance of Think Tanks in Political Decision-making”, Studies of Humanities and Social Sciences Magazine, Vol. No. 2, Issue No. 3.

12. Deshmukh, RANJITSINH A., and R. A. H. U. L. Hiremath. "Decision making with analytical Hierarchy process for selection of furnace for foundry industry." Int. J. Mech. Prod. Eng. Res. Dev 8.4 (2018). 
13. John J, Hamer, "The constructive role of think tanks in twenty first century", Asia- Pacific Review, Vol, 15, No 2, pp2-5, $2008,2-3$

14. MURRY, RENABENI T., and LATA PUJAR. "INFLUENCE OF SOCIOECONOMIC STATUS ON CAREER DECISION MAKING OF UNDERGRADUATE EMERGING ADULTS." International Journal of Educational Science and Research (IJESR)7.5, Oct 2017, 55-62

15. Mohamood, Ahmad, "Use think tanks and the politics of expertise, Role, Value and impact", The political quarterly, Vol. 79, No, 4, October, December, PP529-555, 2008 